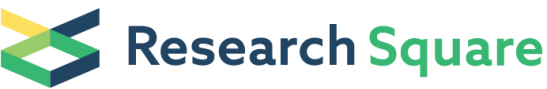 \\ Preprints are preliminary reports that have not undergone peer review. \\ They should not be considered conclusive, used to inform clinical practice, or referenced by the media as validated information.
}

\section{Analysis of the Retina, Choroid, and Optic Nerve Structures using Optical Coherence Tomography in Patients Recovered from Coronavirus Disease 2019}

\author{
Alev Ozcelik Kose ( $\square$ alev_ozcelik@hotmail.com ) \\ Istanbul Haydarpasa Numune Egitim ve Arastirma Hastanesi \\ Nursal Melda Yenerel \\ İstanbul Haydarpaşa Numune Eğitim ve Araştırma Hastanesi: Istanbul Haydarpasa Numune Egitim ve \\ Arastirma Hastanesi
}

\section{Sevcan Balcı}

Haydarpasa Numune Egitim ve Arastirma Hastanesi: Istanbul Haydarpasa Numune Egitim ve Arastirma Hastanesi

\section{Merve Beyza Yıldız}

Haydarpasa Numune Egitim ve Arastirma Hastanesi: Istanbul Haydarpasa Numune Egitim ve Arastirma Hastanesi

\section{Serhat Imamoglu}

Haydarpasa Numune Egitim ve Arastirma Hastanesi: Istanbul Haydarpasa Numune Egitim ve Arastirma Hastanesi

\section{Mehmet Serhat Mangan}

Haydarpasa Numune Egitim ve Arastirma Hastanesi: Istanbul Haydarpasa Numune Egitim ve Arastirma Hastanesi

\section{Research Article}

Keywords: Choroid, COVID-19, retina, optic coherence tomography, optic nerve

Posted Date: September 27th, 2021

DOl: https://doi.org/10.21203/rs.3.rs-435918/v1

License: (c) (1) This work is licensed under a Creative Commons Attribution 4.0 International License. Read Full License 


\section{Abstract}

Purpose: To evaluate retina, choroid and optic nerve in patients recovered from coronavirus disease 2019 (COVID-19).

Methods: Fifty healthcare professionals who had COVID-19 infection- confirmed with polymerase chain reaction from nasopharyngeal swabs- and were at least one-month swab specimen negativeness after the treatment (CG) compared with 40 sex-matched healthy controls ( $\mathrm{HG})$. The dilated fundoscopy examination and optical coherence tomography (OCT) scanning were performed. The fundoscopy examination, subfoveal and peripapillary choroidal vascularity index (CVI), retinal nerve fiber layer (RNFL) and Bruch membrane opening (BMO)-minimum rim width (MRW) were evaluated.

Results: The mean subfoveal and peripapillary CVI were found significantly higher in the CG than the HG ( $p<0.001, p<0.001)$. In the CG, two $(4 \%)$ patients had cotton-wool spot (CWS), one (2\%) patients had retinal hemorrhage.

Discussion: COVID-19 might be associated with increased subfoveal and peripapillary CVI and retinal changes after the healing period.

\section{Introduction}

A novel coronavirus disease, which first emerged in December 2019 in Wuhan, Hubei Province, China, has rapidly spread worldwide, affecting more than 123 million people and caused the death of more than 2.7 million people. The initial cases were reported from December 8th, 2019, among people who worked at or lived around the Huanan Seafood Wholesale Market, and the World Health Organization (WHO) declared the outbreak as a pandemic on March 11th, $2020(1,2)$. The Coronavirus Working Group named this new type of coronavirus acute respiratory syndrome coronavirus 2 (SARS-CoV-2) and its causes as coronavirus disease 2019 (COVID-19).

It is known that coronaviruses mainly affect the respiratory system, but they also have an affinity for the gastrointestinal system, central nervous system, and ocular tissues $(3,4)$. SARS-CoV-2, which is a positive-sense, single-stranded ribonucleic acid (ssRNA+) virus from the genus Beta-coronavirus, enters into the human cells using the angiotensin-converting enzyme 2 (ACE 2 ) receptor in the host (5-7). In the disease's pathogenesis, respiratory droplets carrying SARS-CoV-2 infect epithelial and endothelial cells, neurons, microglia, and lung macrophages containing ACE-2 and viral replication and release damageassociated molecules, causing a dysfunctional innate immune response. Pro-inflammatory agents induce a cytokine storm after infecting the virus, increasing vasodilation, capillary permeability, and hypoxemia (8). The most characteristic clinical course of patients with severe COVID-19 is the development of acute respiratory distress syndrome. Coagulopathy is the other major problem in patients with severe COVID-19, especially those with comorbid diseases. There have also been published cases of systemic thrombotic microangiopathy (TMA) secondary to COVID-19 $(9,10)$. Another noticeable feature of the virus is its ability for neurotropism $(11,12)$. 
ACE-2 receptors are also expressed on many different cell types in the ocular tissues such as the ciliary body, aqueous humour, choroid, retina, and retinal pigment epithelium (13-15). In animal models, coronaviruses have been shown to cause conjunctivitis, uveitis, choroiditis, retinitis, and optical neuritis (16). There are published studies showing conjunctival hyperemia, chemosis, epiphora, and increased secretion in the middle phase of the disease in patients with COVID-19 pneumonia, and studies documenting retinal microhemorrhage, cotton wool spot (CWS), ganglion cells within the papillomacular area, and hyperreflective lesions between the inner plexiform layers in patients with symptomatic COVID$19(17-20)$.

Ocular tissues with dense vascular structures are one of the common involvement sites for systemic diseases. Based on the SARS-CoV-2 virus causing microangiopathy and having neurotropism features, the current study investigated the effects of SARS-CoV-2 and COVID-19 on the retina, choroid, and optic nerve structures using spectral-domain optical coherence tomography (SD-OCT) after the healing period of the disease.

\section{Materials And Methods}

\section{Study Population}

This observational, comparative cross-sectional study included 100 eyes of 50 healthcare professionals (physicians, nurses, and technicians), who had COVID-19 infection- confirmed with reverse transcription polymerase chain reaction from nasopharyngeal swab samples- and were at least one-month swab samples negativeness after the treatment. The age-matched control subjects comprised of the physicians, nurses, and technicians who were imaged on the SD-OCT in 2019 as a part of prior study and worked at the Haydarpasa Numune Training and Research Hospital. The study was conducted in accordance with the principles of the Helsinki Declaration, and approval was obtained from the local clinical trials ethics committee. All subjects signed informed consent forms.

\section{Inclusion and Exclusion Criteria}

In the COVID-19 group (CG), all participants had a positive SARS-CoV-2 polymerase chain reaction (PCR) test result for nasopharyngeal swab specimens taken while infected with the disease, and patients with PCR negativity at least one-month after the treatment. None of the participants had ocular or systemic symptoms.

Inclusion criteria for all participants were as follows: (1) a corrected intraocular pressure (IOP) of $\leq 20$ $\mathrm{mm} \mathrm{Hg}$ according to central corneal thickness (CCT), (2) best-corrected visual acuity (BCVA) of $\geq 6 / 10$, (3) spherical refractive errors of -4 to +3 diopters and cylindrical refractive errors of $\leq 3$ diopters, (4) absence of any ocular or systemic disease and history of systemic or topical drug use. The exclusion criteria included glaucomatous damage to the optic disc (OD) in fundus examination; family history of glaucoma; the history of retinal diseases; poor image quality due to severe cataracts, corneal opacity, pupillary anomaly, vitreous opacity, and history of ocular surgery. 
All participants underwent BCVA assessment, slit-lamp examinations and fundus was screened with dilated fundoscopy. During dilated fundoscopy examination if the retinal lesions were observed, the color fundus photography (Carl Zeiss Meditec, Germany) were also taken.

\section{Optical Coherence Tomography Imagining}

SD-OCT scanning (Spectralis ${ }^{\circledR}$, Heidelberg Engineering $\mathrm{GmbH}$, Heidelberg, Germany) was performed for all patients. All OCT imaging procedures were performed by a single experienced operator from 9.00 to 10.00 a.m., and the high (>20) quality scores were tried to be sustained.

The central macular thickness and volume were measured at a $1 \mathrm{~mm}$ diameter fovea area of the topographic thickness map in nine zone maps as defined by the Early Treatment Diabetic Retinopathy

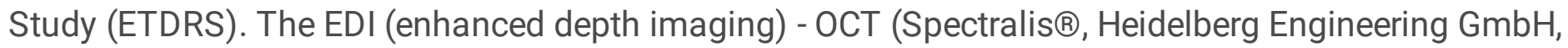
Heidelberg, Germany) technique was used to obtain choroidal images of the subfoveal and peripapillary region. At least two high-quality horizontal and vertical scans were taken from the fovea for each eye. 1024 A-scans on a $6 \mathrm{~mm}$ horizontal line passing through the center of the fovea were obtained from all participants. In EDI mode, standard settings were used: 25 horizontal plane scanning, 20x20 degrees, 240 $\mathrm{mm}$ linear distance, automatic real-time. For the peripapillary region, 360-degree $3.4 \mathrm{~mm}$ diameter circle scans were used, centered on the optic disc. Choroidal thickness was defined as the vertical distance between the hyper-reflective outer border of the retinal pigment epithelium (RPE) and the inner border of the chorioscleral junction. The subfoveal area from the retinal pigment epithelium to the chorioscleral junction was marked from $750 \mu \mathrm{m}$ nasal and $750 \mu \mathrm{m}$ temporal to the fovea. The EDI-OCT images were binarized using the Image $\mathrm{J}$ software (Version 1.52i, National Institutes of Health, Bethesda, MD USA) with the protocol described by Agrawal et al. (21) (Fig. 1). The images of the total choroidal area (TCA) marked for peripapillary and subfoveal regions were binarized using Niblack's auto local thresholding method. The luminal area ( $L A)$ was identified by first converting the image to red-blue-green (RBG) and then applying the color threshold. In the ROI manager, the first automatically calculated value represents TCA and the second value represents LA. The stromal area (SA) was calculated by subtracting LA from TCA, and CVI was computed by dividing LA by TCA. All CVI measurements were performed by the same observer who was blinded to the diagnosis of the participant's images, and all CVI measurements were repeated three times. The average values were selected for the analysis.

The Bruch membrane opening (BMO)-minimum rim width (MRW) and the peripapillary retinal nerve fiber layer (RNFL) thickness were measured using the Glaucoma Module Premium Edition (GMPE) software. The BMO-MRW imagining protocol is comprising of 24 equally spaced radial B-scans, each with $768 \mathrm{~A}$ scans covering a 15-degree region centered on the optic disc. For each scan location, 25 B-scans were averaged automatically. RNFL thickness was measured with a circular scan, 12 degrees in diameter, centered on the BMO centroid.

In the $C G$, symptoms and laboratory findings including complete blood count, erythrocyte sedimentation rate (ESR), C-reactive protein (CRP), ferritin, prothrombin time, international normalized ratio, lactic acid 
dehydrogenase, D-dimer, creatinine, creatine kinase, and albumin that were taken at the first admission to the COVID-19 outpatient clinics were noted from the hospital records.

The SPSS 21.0 software for Mac (IBM SPSS, Chicago, IL, USA) was used for statistical analysis. The Kolmogorov-Smirnov test was used for distribution analysis. The Chi-square test was used for differences in categorical values. Independent samples t-test was used for the normally distributed data. Non-normally distributed data were compared using the Wilcoxon and Mann-Whitney $U$ tests. Regression analyses were adjusted for covariates such as age, sex, refractive errors, IOP, systemic diseases, smoking, and alcohol consumption. Simple linear regression analysis was performed to evaluate the effect of clinical and laboratory variables on retinal findings, subfoveal and peripapillary CVI in the CG. Multiple linear regression analysis was performed to determine variables that had a significant effect. A value of $p<0.05$ was considered statistically significant. The R software version 3.2.2 and the R package eRm were used for statistical analyses.

\section{Results}

There were 50 patients ( 31 females, 19 males, mean age: $31.9 \pm 0.72$ years) in the CG and 40 patients (20 females, 20 males, mean age: $34.7 \pm 1.22$ years) in the HG. There were no statistically significant differences regarding age and sex distribution $(p=0.09, p=0.08)$. In the $C G$, the mean evaluation time was $2.05 \pm 0.5$ months after COVID-19 test positivity. For assessing the severity of COVID-19, $94 \%$ of the CG had mild-to-moderate disease or were asymptomatic, and $6 \%$ developed a severe disease that required supplemental oxygen; no patients had the critical disease or a need the intensive care unit during the infection period. One patient developed lower extremity deep vein thrombosis as a complication associated with COVID-19. The detailed demographic characteristics, clinical features, laboratory parameters, and treatment agents by groups are presented in Table 1. 


\begin{tabular}{|c|c|c|c|}
\hline \multicolumn{4}{|c|}{$\begin{array}{l}\text { Table } 1 \\
\text { Patient Characteristics }\end{array}$} \\
\hline & Covid $(n=50)$ & Control $(n=40)$ & p \\
\hline Mean age (years \pm SD) & $31.9 \pm 0.72$ & $34.7 \pm 1.22$ & $0.09 *$ \\
\hline Gender F/M & $31: 19$ & $20: 20$ & $0.08^{\#}$ \\
\hline BCVA Snellen ( \pm SD) & 1 & 1 & $1 *$ \\
\hline Spheric (D $\pm S D)$ & $0.3 \pm 0.1$ & $0.25 \pm 0.12$ & $0.87 * \star$ \\
\hline IOP (mmHg \pm SD) & $13.9 \pm 0.22$ & $13.8 \pm 0.22$ & $0.77 * \star$ \\
\hline $\mathrm{CCT}(\mu \mathrm{m} \pm \mathrm{SD})$ & $559.2 \pm 2.95$ & $555.6 \pm 2.54$ & $0.24 *$ \\
\hline $\mathrm{AL}(\mathrm{mm} \pm \mathrm{SD})$ & $23.3 \pm 0.07$ & $23.2 \pm 0.11$ & $0.14 *$ \\
\hline Covid 19 Clinical Features (\%) & & NA & \\
\hline Asymptomatic & 24 & & \\
\hline Fever & 40 & & \\
\hline Cough & 38 & & \\
\hline Fatigue & 20 & & \\
\hline Dyspnoea & 14 & & \\
\hline Sore Throat & 8 & & \\
\hline Headache & 10 & & \\
\hline Gastrointestinal Issues & 8 & & \\
\hline Anosmia & 4 & & \\
\hline Conjunctivitis & 4 & & \\
\hline Laboratory Parameters & & NA & \\
\hline WBC $(\times 109 / L \pm S D)$ & $6328.3 \pm 0.45$ & & \\
\hline Neutrophils ( ×109/L \pm SD) & $3657.8 \pm 0.30$ & & \\
\hline Lymphocytes (×109/L \pm SD) & $1976.7 \pm 0.21$ & & \\
\hline Platelets (×109/L \pm SD) & $224.7 \pm 16.7$ & & \\
\hline D-Dimer $(\mu \mathrm{g} / \mathrm{L} \pm \mathrm{SD})$ & $489 \pm 359.3$ & & \\
\hline $\mathrm{CRP}(\mathrm{mg} / \mathrm{L} \pm \mathrm{SD})$ & $0.89 \pm 0.25$ & & \\
\hline Ferritin $(\mu \mathrm{g} / \mathrm{L} \pm \mathrm{SD})$ & $103.5 \pm 26.5$ & & \\
\hline
\end{tabular}


Table 1

Patient Characteristics

\begin{tabular}{ll} 
Sedimantation $(\mathrm{mm} / \mathrm{h} \pm \mathrm{SD})$ & $36.2 \pm 11.76$ \\
\hline $\mathrm{PT}(\mathrm{s} \pm \mathrm{SD})$ & $13.8 \pm 0.75$ \\
\hline $\mathrm{INR}($ ratio $\pm \mathrm{SD})$ & $1.02 \pm 0.05$ \\
\hline Albumin $(\mathrm{g} / \mathrm{L} \pm \mathrm{SD})$ & $45.6 \pm 2.01$ \\
\hline $\mathrm{LDH}(\mathrm{U} / \mathrm{L} \pm \mathrm{SD})$ & $198.2 \pm 33.04$ \\
\hline Creatinine $(\mathrm{mg} / \mathrm{dL} \pm \mathrm{SD})$ & $0.82 \pm 0.11$ \\
\hline Creatine Kinase $(\mathrm{U} / \mathrm{L} \pm \mathrm{SD})$ & $107.6 \pm 58.2$ \\
\hline
\end{tabular}

Treatment Agents (\%)

NA

Hydroxychloroquine

90

Favipiravir

24

Enoxaparin

18

Azithromycin

20

O2 supply

34

AL, axial length; BCVA, best-corrected visual acuity; CCT, central corneal thickness; CRP, C-Reactive Protein; IOP, intraocular pressure; ESR, erythrocyte sedimentation rate; INR, international normalized ratio; LDH, Lactic acid Dehydrogenase; NA, not available; PT, Prothrombin Time; WBC, White Blood Cells. " ${ }^{\#}$ Chi-square test; *Independent sample t-test; ** Mann-Whitney test.

In the evaluation of OCT results, the mean macular thickness was $266 \pm 15 \mu \mathrm{m}$ in the CG and $265 \pm 18 \mu \mathrm{m}$ in the HG $(p=0.54)$. There was no significant difference in BMO-MRW and RNFL thickness between the groups ( $p=0.065$ and $p=0.065$, respectively). The $C G$ had a higher mean subfoveal TCA than the HG $\left(1.85 \pm 0.02 \mathrm{~mm}^{2}\right.$ vs. $1.42 \pm 0.05 \mathrm{~mm}^{2}$, respectively), and also higher LA compared with the HG (1.30 \pm $0.01 \mathrm{~mm}^{2}$ vs. $\left.0.91 \pm 0.13 \mathrm{~mm}^{2} \mathrm{p}<0.001\right)$. The mean subfoveal CVI \% value was $70.27 \pm 2.47 \%$ in the CG, and $64.08 \pm 0.22 \%$ in the HG $(p<0.001)$. In the peripapillary choroidal region, the CG had higher TCA and LA than the HG $\left(7.85 \pm 0.10 \mathrm{~mm}^{2}\right.$ vs. $6.97 \pm 1.16 \mathrm{~mm}^{2}, 5.46 \pm 0.01$ vs. $4.53 \pm 0.04 \mathrm{~mm}^{2}$ respectively; $p<$ $0.001)$. The mean peripapillary CVI was $69.6 \pm 3.41 \%$ in the CG and $65.02 \pm 2.29 \%$ in the HG $(p<0.001)$ (Table 2). In the CG, two (4 \%) patients had CWS, one (2\%) patient had retinal hemorrhage. 
Table 2

OCT Measurements of the Participants in Covid and Control Groups

\begin{tabular}{|c|c|c|c|}
\hline & $\begin{array}{l}\text { COVID-19 }(n=50) \\
\text { mean } \pm \text { SD }\end{array}$ & $\begin{array}{l}\text { Control }(n=40) \\
\text { mean } \pm \text { SD }\end{array}$ & p \\
\hline MT $\mu \mathrm{m}$ & $266 \pm 15$ & $265 \pm 18$ & $0.540^{+}$ \\
\hline $\mathrm{MV} \mu \mathrm{m}$ & $0.2 \pm 0.00$ & $0.2 \pm 0.20$ & $0.82^{\dagger}$ \\
\hline Global RNFLT $\mu \mathrm{m}$ & $104.06 \pm 1.09$ & $101.03 \pm 1.23$ & $0.065^{\dagger}$ \\
\hline Global BMO-MRW $\mu \mathrm{m}$ & $363.05 \pm 7.44$ & $346.33 \pm 5.76$ & $0.060^{+}$ \\
\hline SF TCA mm² & $1.85 \pm 0.02$ & $1.42 \pm 0.05$ & $0.000^{\dagger}$ \\
\hline SF LA mm² & $1.30 \pm 0.01$ & $0.91 \pm 0.13$ & $0.000^{+\dagger}$ \\
\hline SF SA mm² & $0.55 \pm 0.007$ & $0.51 \pm 0.01$ & $0.126^{{ }^{+}}$ \\
\hline SF CVI \% & $70.27 \pm 2.47$ & $64.08 \pm 3.22$ & $0.000^{\dagger+}$ \\
\hline PP TCA mm² & $7.85 \pm 0.10$ & $6.97 \pm 1.16$ & $0.002^{\dagger}$ \\
\hline PP LA mm² & $5.46 \pm 0.01$ & $4.53 \pm 0.04$ & $0.000^{\dagger+}$ \\
\hline PP SA mm² & $2.39 \pm 0.08$ & $2.44 \pm 0.11$ & $0.180^{\dagger}$ \\
\hline PP CVI \% & $69.6 \pm 3.41$ & $65.02 \pm 2.29$ & $0.000^{\dagger}$ \\
\hline \multicolumn{4}{|c|}{$\begin{array}{l}\text { BMO-MRW, Bruch membrane opening - minimum rim width; CVI, choroidal vascularity index; MT, } \\
\text { macular thickness; MV, macular volume; LA, luminal area; PP, peripapillary; RNFLT, peripapillary retina } \\
\text { nerve fiber layer thickness; SA, stromal area; TCA, total choroidal area. } \\
{ }^{+} \text {Independent sample t-test; }{ }^{\dagger+} \text { Mann-Whitney test. }\end{array}$} \\
\hline
\end{tabular}

Multiple regression analysis showed no statistically significant relationship between the subfoveal and peripapillary CVI and patients' age, sex, refractive errors, AL, CCT, IOP, clinical and laboratory variables ( $p$ > 0.05).

\section{Discussion}

The present study investigated the retinal findings, macular thickness, subfoveal and peripapillary CVI, RNFL, and BMO-MRW using OCT in patients recovered from COVID-19. Retinal hemorrhage and CWS were observed as the retinal findings in the CG. In the choroidal region, the mean subfoveal and peripapillary CVI were significantly higher than in the HG. Although the difference was not statistically significant, the mean RNFL thickness was $3 \mu \mathrm{m}$, and the mean BMO-MRW was $17 \mu \mathrm{m}$ thicker compared with the HG. 
Ocular findings, which are thought to be associated with the COVID-19, are reported in recent publications. (17-22). The detection of the virus in the retinal biopsies of who died from COVID-19 proved the presence of the virus in retinal layers (23). The retinal hemorrhages, dilated veins, tortuous vessels and CWS due to retinal microangiopathy caused by COVID-19 were the most cited signs in the studies $(18,19)$. The CWS in the retinal region is most commonly associated with diabetes mellitus, AIDS, and systemic hypertension. It occurs secondary to ischemia-induced by retinal arteriole obstruction (24). Factors that interrupt the focal axoplasmic flow in the retinal nerve fiber layer lead to the accumulation of intra-axonal organelles (25). SARS-CoV-2 has been shown to cause endotheliitis and vasculitis due to direct viral infection of endothelial cells in arterial and venous circulations $(26,27)$. Endotheliitis causes microvascular dysfunction and tissue ischemia. In the present study, we evaluated asymptomatic individuals who had not previously known systemic diseases and recovered from COVID-19 and, interestingly, found two patients with CWS and one with retinal hemorrhage after the recovery period. Although it is hard to conclude that these findings directly resulted from COVID-19, all systemic investigations were regular in these patients, so we thought these conditions might be associated with SARS-CoV-2.

The dense vascular choroid layer is one of the structures influenced by many physiologic variables and disorders such as systemic inflammation, infections, and vascular disorganization (28). Choroidal changes in viral infection/inflammation might play an essential role in several posterior segment diseases because the choroid supplies blood flow to the retinal pigmented epithelium, photoreceptors, and the prelaminar portion of the optic nerve (29-31). Agrawal et al. suggested that CVI might be a better and relatively more stable and objective quantitative marker to analyze choroid than choroidal thickness alone (21). Other coronaviruses have been shown only to cause choroiditis in animal models (16). In the current study, subfoveal and peripapillary CVI were significantly higher in the CG than the HG. Both LA and SA may have been affected by the combination of hemodynamic instability and systemic immunologic process created by direct viral infection/inflammation. It is not clear whether the affection in the choroidal area is due to an inflammatory response to the virus or the known endothelial damage characteristic of the virus. Invernizzi et al. found significant enlargement in the mean retinal arteries and vein diameters in patients COVID-19 who had symptoms within 30 days. They reported these changes might have had similar mechanisms with the reported pulmonary vascular enlargement $(18,32)$. This dilation was explained by the increased blood flow due to the inflammatory response $(18,32)$. Savastano et al. reported that subfoveal choroid was thicker $(310.463 \pm 81.60 \mu \mathrm{m})$ in post-COVID-19 disease compared with healthy controls $(293.5 \pm 86.56 \mu \mathrm{m})(33)$. We also found that subfoveal and peripapillary choroidal vascular areas were also had enlargement compared with the controls.

There is evidence indicating that coronaviruses cause optic neuritis in animal models, and SARS-CoV-2 has a potential neurotropic effect $(11,16,34,35)$. Burgos-Blasco et al. reported a mean $4.3 \mu \mathrm{m}$ increase in RNFL thickness compared with previous data in patients with COVID-19 (35). We found similar results in patients recovered from COVID-19. The mean RNFL and BMO-MRW were thicker than in the HG, but these changes were not statistically significant. SARS-CoV-2 might affect the optic nerve by inflammation, or its direct neurotrophic effect may lead to increased RNFL thickness and BMO-MRW. 
The limited number of study subjects and the absence of OCT results obtained before or at the acute phase of the disease are the limitations of this study. The lack of long-term consequences, the correlation between CVI changes and indocyanine green angiography and optical coherence tomography angiography is also a weakness of our study. Studies with larger populations and more prolonged duration may contribute to better evaluations of the effects of SARS-CoV-2 on the retina, choroid, and optic nerve.

In conclusion, the study's patient group consisted of young, healthy healthcare workers without any known systemic disease, all of whom were affected by COVID-19, a mean of $2.05 \pm 0.5$ months ago. We suggest that this study's retinal and choroidal results should be considered to be related to SARS-CoV-2. To the best of our knowledge, this study showed for the first time that SARS-CoV-2 might lead to an increase in subfoveal and peripapillary CVI values after recovery. Prospective studies with larger populations will contribute to our understanding of the impact of COVID-19 on the eye.

\section{Declarations}

\section{Acknowledgments}

\section{Author Contributions}

Conceptualization: Alev Ozcelik Kose; Methodology: Alev Ozcelik Kose, Sevcan Balci; Formal analysis and investigation: Alev Ozcelik Kose, Nursal Melda Yenerel; Writing - original draft preparation: Alev Ozcelik Kose, Nursal Melda Yenerel, Sevcan Balci; Writing - review and editing: Alev Ozcelik Kose, Nursal Melda Yenerel, Sevcan Balci, Merve Beyza Yıldız, Serhat Imamoglu, Mehmet Serhat Mangan.

\section{Declaration of interest statement}

We declare no conflict of interest.

\section{Funding}

No funding was received for this research.

\section{Compliance with ethical standards}

All procedures performed in studies involving human participants were in accordance with the ethical standards of the University of Health Sciences, Istanbul, Turkey and with the 1964 Helsinki Declaration. 


\section{Informed consent}

Informed consent was obtained from all individual participants included in the study.

\section{References}

1. Lu H, Stratton CW, Tang YW (2020) Outbreak of pneumonia of unknown etiology in Wuhan China: the mystery and the miracle. J Med Virol 92(4):401-402

2. Note from the editors (2020) World Health Organization declares novel coronavirus (2019-nCoV) sixth public health emergency of international concern. Euro Surveill 25(5):200131e

3. Loon S-C, Teoh SCB, Oon LLE et al (2004) The severe acute respiratory syndrome coronavirus in tears. British J Ophthalmol 88(7):861-863

4. Yeo C, Kaushal S, Yeo D (2020) Enteric involvement of coronaviruses: is faecal \& oral transmission of SARS-CoV-2 possible? Lancet Gastroenterol Hepatol 5(4):335-337

5. Lu R, Zhao X, Li J et al (2020) Genomic characterisation and epidemiology of 2019 novel coronavirus: implications for virus origins and receptor binding. Lancet 22(10224):565-574 395 )

6. Kramer A, Schwebke I, Kampf G (2006) How long do nosocomial pathogens persist on inanimate surfaces? A systematic review. BMC Infect Dis 6:130

7. Hamashima K, Gautam P, Lau KA et al (2020) Potential modes of COVID-19 transmission from human eye revealed by single-cell atlas. BioRxiv [Internet]

8. Machhi J, Herskovitz J, Senan A et al (2020) The Natural History, Pathobiology, and Clinical Manifestations of SARS-CoV-2 Infections. J Neuroimmune Pharmacol 15(3):359-386

9. Fan BE, Chong VCL, Chan SSW (2020) Hematologic parameters in patients with COVID-19 infection. Am J Hematol 95(6):E131-E134

10. Gavriilaki E, Brodsky RA (2020) Severe COVID-19 infection and thrombotic microangiopathy: success doesn't come easily. $\mathrm{Br} \mathrm{J}$ Haematol 186:e227-e230

11. Baig AM, Khaleeq A, Ali U et al (2020) Evidence of the COVID-19 virus targeting the CNS: tissue distribution, host-virus interaction, and proposed neurotropic mechanisms. ACS Chem Neurosci 1;11(7):995-998

12. Li YC, Bai WZ, Hashikawa T (2020) The neuroinvasive potential of SARS-CoV2 may play a role in the respiratory failure of COVID-19 patients. J Med Virol 92(6):552-555

13. Wan Y, Shang J, Graham R et al (2020) Receptor recognition by novel coronavirus from Wuhan: an analysis based on decade-long structural studies of SARS. J Virol 17(7):e00127-e00120 94 )

14. Holappa $M$, Vapaatalo $H$, Vaajanen $A$ (2017) Many faces of renin-angiotensin system - focus on eye. Open Ophthalmol J 11(1):122-142

15. Strain WD, Chaturvedi N (2002) Review: the renin-angiotensin-aldosterone system and the eye in diabetes. J Renin-Angiotensin-Aldosterone Syst 3(4):243-246 
16. Seah I, Agrawal R (2020) Can the coronavirus disease 2019 (COVID-19) affect the eyes? A review of coronaviruses and ocular implications in humans and animals. Ocul Immunol Inflamm 28:391-395

17. Wu P, Duan F, Luo C et al (2020) Characteristics of ocular findings of patients with coronavirus disease 2019 (COVID-19) in Hubei Province, China. JAMA Ophthalmol 138(5):575-578

18. Invernizzi A, Torre A, Parrulli S et al (2020) Retinal findings in patients with COVID-19: Results from the SERPICO-19 study. E Clinical Medicine 27:100550

19. Landecho MF, Yuste JR, Gándara E et al (2021) COVID-19 retinal microangiopathy as an in vivo biomarker of systemic vascular disease? J Intern Med 289(1):116-120

20. Abrishami M, Emamverdian Z, Shoeibi N et al (2020) Optical coherence tomography angiography analysis of the retina in patients recovered from COVID-19: a case-control study. Can J Ophthalmol 14: S0008-4182(20)30813-9

21. Agrawal R, Gupta P, Tan KA et al (2016) Choroidal vascularity index as a measure of vascular status of the choroid: measurements in healthy eyes from a population-based study. Sci Rep 6:21090

22. Chen L, Liu M, Zhang Z et al (2020) Ocular manifestations of a hospitalized patient with confirmed 2019 novel coronavirus disease. $\mathrm{Br} \mathrm{J}$ Ophthalmol 104(6):748-751

23. Casagrande M, Fitzek A, Püschel K et al (2020) Detection of SARS-CoV-2 in Human Retinal Biopsies of Deceased COVID-19 Patients. Ocul Immunol Inflamm 3;28(5):721-725

24. Patel PS, Sadda SR (2012) Retinal Artery Obstructions. In Retina (Fifth Edition), by Ryan SJ 10121025

25. McLeod D, Marshall J, Kohner EM et al (1977) The role of axoplasmic transport in the pathogenesis of retinal cotton-wool spots. Br J Ophthalmol 61(3):177-191

26. Varga Z, Flammer AJ, Steiger $P$ et al (2020) Endothelial cell infection and endotheliitis in COVID-19. Lancet 395:1417-1418

27. Hanafi R, Roger PA, Perin B et al (2020) COVID-19 neurologic complication with CNS vasculitis-like pattern. AJNR Am J Neuroradiol 41(8):1384-1387

28. Ingegnoli F, Gualtierotti R, Pierro L et al (2015) ACUTE study group: Choroidal impairment and macular thinning in patients with systemic sclerosis: the ACUTE study. Microvasc Res 97:31-36

29. Hayreh SS (1969) Blood supply of the optic nerve head and its role in optic atrophy, glaucoma, and oedema of the optic disc. Br J Ophthalmol 53(11):721-748

30. Kur J, Newman EA, Chan-Ling T (2012) Cellular and physiological mechanisms underlying blood flow regulation in the retina and choroid in health and disease. Prog Retin Eye Res 31(5):377-406

31. Linsenmeier RA, Padnick-Silver $L$ (2000) Metabolic dependence of photoreceptors on the choroid in the normal and detached retina. Invest Ophthalmol Vis Sci 41(10):3117-3123

32. Zhou S, Wang Y, Zhu T et al (2020) CT Features of Coronavirus Disease 2019 (COVID-19) Pneumonia in 62 Patients in Wuhan, China. AJR Am J Roentgenol 214(6):1287-1294

33. Savastano A, Crincoli E, Savastano MC et al Gemelli Against Covid-Post-Acute Care Study Group (2020) Peripapillary Retinal Vascular Involvement in Early Post-COVID-19 Patients. J Clin Med 


\section{8;9(9):2895}

34. Li YC, Bai WZ, Hashikawa T (2020) The neuroinvasive potential of SARS-CoV2 may play a role in the respiratory failure of COVID-19 patients. J Med Virol 92(6):552-555

35. Burgos-Blasco B, Güemes-Villahoz N, Donate-Lopez J et al (2020) Optic nerve analysis in COVID-19 patients. J Med Virol 93(1):190-191

\section{Figures}

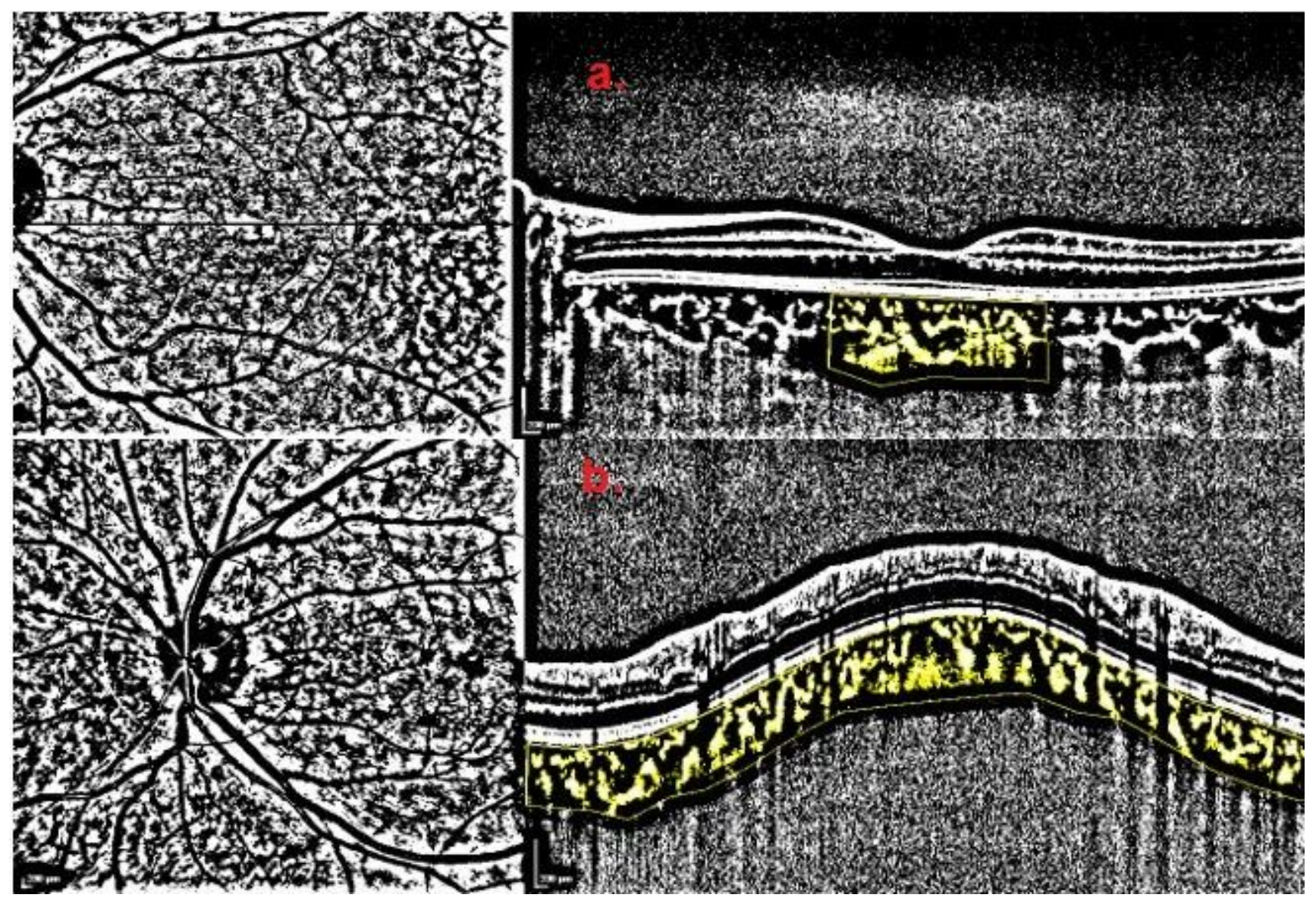

Figure 1

Illustration of binarisation EDI-OCT images in the subfoveal (a) and peripapillary (b) area. 